\title{
Gene therapy for the treatment of cystic fibrosis
}

\author{
This article was published in the following Dove Press journal: \\ The Application of Clinical Genetics \\ 17 July 2012 \\ Number of times this article has been viewed
}

\author{
Tabinda J Burney 1,2 \\ Jane C Davies ${ }^{1,2,3}$ \\ 'Department of Gene Therapy, \\ Imperial College London, ${ }^{2}$ UK \\ CF Gene Therapy Consortium \\ London, ${ }^{3}$ Department of Paediatric \\ Respiratory Medicine, Royal \\ Brompton and Harefield NHS \\ Foundation Trust, London, UK
}

Correspondence: Jane C Davies Department of Gene Therapy, National Heart and Lung Institute, Emmanuel Kaye Building, Manresa Road, London, SW3 6LR, UK

Tel +4420735I 8398

Fax +44 20735 I 8340

Email j.c.davies@imperial.ac.uk
Abstract: Gene therapy is being developed as a novel treatment for cystic fibrosis (CF), a condition that has hitherto been widely-researched yet for which no treatment exists that halts the progression of lung disease. Gene therapy involves the transfer of correct copies of cystic fibrosis transmembrane conductance regulator (CFTR) DNA to the epithelial cells in the airways. The cloning of the CFTR gene in 1989 led to proof-of-principle studies of CFTR gene transfer in vitro and in animal models. The earliest clinical trials in CF patients were conducted in 1993 and used viral and non-viral gene transfer agents in both the nasal and bronchial airway epithelium. To date, studies have focused largely on molecular or bioelectric (chloride secretion) outcome measures, many demonstrating evidence of CFTR expression, but few have attempted to achieve clinical efficacy. As CF is a lifelong disease, turnover of the airway epithelium necessitates repeat administration. To date, this has been difficult to achieve with viral gene transfer agents due to host recognition leading to loss of expression. The UK Cystic Fibrosis Gene Therapy Consortium (Imperial College London, University of Edinburgh and University of Oxford) is currently working on a large and ambitious program to establish the clinical benefits of CF gene therapy. Wave 1, which has reached the clinic, uses a non-viral vector. A single-dose safety trial is nearing completion and a multi-dose clinical trial is shortly due to start; this will be powered for clinically-relevant changes. Wave 2, more futuristically, will look at the potential of lentiviruses, which have long-lasting expression. This review will summarize the current status of translational research in CF gene therapy.

Keywords: cystic fibrosis transmembrane conductance regulator (CFTR) gene, gene expression, gene transfer agents (GTAs), outcome measures

\section{Introduction}

Cystic Fibrosis (CF) is an autosomal recessive, life-limiting disease resulting from mutations in the cystic fibrosis transmembrane conductance regulator (CFTR) gene. The gene is comprised of 27 exons and is situated on chromosome 7 . The protein encoded by the CFTR gene is a cAMP-regulated chloride channel situated in the apical membrane of exocrine epithelial cells; ${ }^{1}$ other processes with which it is involved include regulation of the epithelial sodium channel, and bicarbonate transport. There is conflicting evidence on its role in regulating the $\mathrm{pH}$ of intracellular organelles and the consequences on cellular processes such as sialylation and sulfation. In patients with CF, CFTR protein function may be abnormal due to a lack of production (Class 1 mutations), failure to reach its site of action due to misfolding (Class 2; commonest Caucasian defect is Phe508Del), defects in gating (Class 3), conductance (Class 4), abnormally low channel numbers (Class 5), or decreased half-life (Class 6). 
Whilst the CFTR protein is expressed in many internal organs, the major effect of such mutations is on the respiratory, gastrointestinal, and reproductive tracts, causing, in each of these sites, obstruction by thick, viscous secretions. Pulmonary disease leads to most of the morbidity associated with $\mathrm{CF}$ and is the cause of death in more than $90 \%$ of patients. $^{2}$ The correlation of the molecular defect with this multi-system clinical picture is complex and not entirely understood. It has been shown that CF airway epithelia have abnormally high rates of sodium (and thus water) absorption, which dehydrates the airway surface liquid and impairs mucus transport. More recently, vibrating culture, which may recapitulate the in vivo setting better than the conventional static culture model, has demonstrated that these processes are well preserved until a "second hit" in the form of viral infection occurs. ${ }^{3}$ Once the airway surface becomes dehydrated, mucociliary clearance (MCC) mechanisms fail to remove any inhaled bacteria, which infect the lower airways and lead to inflammation. The CF inflammatory response is abnormal in several ways, being exaggerated, ${ }^{4}$ prolonged $^{5}$ and, at least in chronic stages of infection, ineffectual. ${ }^{6}$ The presence of inflammatory cell contents such as DNA and elastase in the airway further increase mucus viscosity and contribute to tissue breakdown.

The existing therapeutic modalities for CF lung disease focus mainly on mechanical clearance of airway secretions and the treatment of infection. Antibiotics are the mainstay of treatment; along with improved airway clearance techniques and nutrition, these have contributed to the greatly improved life expectancy and quality of life in recent decades. However, they are palliative measures and are fraught with difficulties of bacterial resistance, cumulative toxicity and their cumbersome and time-consuming nature for patients and families. Even today, more than $90 \%$ of patients die with advanced lung disease unless they receive a transplant. There is, therefore, a pressing need for the development of newer treatment approaches. One such approach is gene therapy which addresses the basic defect rather than the downstream consequences of the disease; along with small molecules directed at CFTR protein function, ${ }^{7}$ such an approach, if successful, has the potential to impact significantly on the natural history of the disease.

Gene therapy, the transfer of copies of the normal CFTR gene to the relevant cells, should theoretically be well-suited to CF as: (1) it is a single-gene disorder; (2) heterozygotes are phenotypically normal, implying that levels do not have to reach those of wild-type; (3) the main target, the airways, is easily accessible via topical routes; and (4) the lungs are normal at birth, indicating a potential therapeutic window. However, in practice, the airways are in fact very difficult targets for gene therapy. The mucociliary escalator has evolved to keep foreign particles out. The layer of mucus that is required for normal ciliary function inhibits gene transfer per se and in CF this barrier is increased as secretions are excessive and abnormally viscous. The host immune response may also be problematic: with viral gene transfer agents, recognition of viral coat proteins and the production of neutralizing antibodies leads to problems with re-administration. ${ }^{8}$ For non-viral gene transfer agents, the plasmid DNA which has been in common use is generally rich in unmethylated $\mathrm{CpG}$ dinucleotides, which are likely to be recognized by humans as foreign and thus produce an inflammatory response..$^{9,10}$

\section{Gene transfer agents}

The transfection efficiency of naked DNA is so low that gene transfer agents (GTAs) have been designed to enhance entry to the cell/nucleus. These fall broadly into viral and non-viral categories, the latter usually lipid-based, but also including nanoparticles. The assumed innate capability of viruses to infect the respiratory tract made them a natural initial choice. Engineered adenovirus (Ad) was used in early $\mathrm{CF}$ clinical trials ${ }^{11}$ but at high titers, some of these reported significant inflammatory responses and unacceptable toxicity; this problem has largely been overcome with the use of new generation viruses. However, in common with many other viruses, the receptor for Ad (CAR), rather than being conveniently located on the apical cell surface, is on the basolateral surfaces ${ }^{12}$ and therefore relatively inaccessible from the airway lumen even in the presence of the inflammation characteristic of CF. Various agents, such as polidocanol ${ }^{13}$ and perflurochemicals, ${ }^{14}$ have been used to break down tight junctions and allow access to such receptors, although the safety and applicability of such approaches in humans remains to be demonstrated.

Adeno-associated virus (AAV) is a small single-stranded DNA member of the Parvovirus family. Owing to its lack of pathogenicity it is theoretically a good vector for gene transfer. However, its receptors are serotype-specific and many are scarce on the apical surface of the airway epithelium. ${ }^{15}$ As it is a small virus, large genes such as CFTR may be difficult to package. Some researchers have attempted to create a functional CFTR "mini gene", ${ }^{16}$ using techniques such as cutting the CFTR in half and using two complementary AAVs.

Sendai virus ( $\mathrm{SeV}$ ), a single-stranded RNA virus, belongs to the family of Paramyxoviridae. It is highly efficient at 
transfecting airway epithelial cells due to the presence of sialic acid and cholesterol receptors on their apical surface. ${ }^{17}$ Another advantage is its cytoplasmic expression, which removes the problem of the nuclear membrane barrier. High levels of gene expression have been reported but, in common with those viruses listed above, the major problem is with repeat administration; host immune responses, both cellular and humoral, may result from the primary administration and lead to reduced or absent gene expression after subsequent exposure. As $\mathrm{CF}$ is a lifelong disease, repeated administration is a required feature of any gene transfer agent targeting the superficial epithelium. The only possible way of avoiding this would be permanently (with an integrating vector) to transfect the stem cells of the airways; ${ }^{18}$ such cells are difficult to reach, being buried beneath the surface and there are justifiable concerns over the use of integrating vectors, which have been shown to induce oncogenesis in gene therapy trials for severe immunodeficiencies. ${ }^{19}$

Lentiviruses are highly efficient gene transfer agents. ${ }^{20,21}$ They have certain advantages over other gene transfer methods including the ability to transfect both dividing and non-dividing cells, and long-term stable expression; they also seem, almost uniquely amongst viruses, to be repeatedly administrable. ${ }^{22}$ However, they naturally target hematopoietic cells and do not possess the surface proteins which recognize receptors on respiratory epithelia. To address this issue, our group, the UK CF Gene Therapy Consortium has recently generated a simian immunodeficiency virus (SIV) pseudotyped with Sendai viral F and HN proteins. This novel chimeric vector leads to high levels of transgene expression, is repeatedly administrable $e^{23}$ and is the focus of our future work (see below).

Non-viral approaches include cationic liposomes, compacted DNA nanoparticles and naked DNA. Cationic liposomes consist of cationic lipids that are usually mixed with cholesterol and dioleoylphosphatidylethanolamine. When combined with DNA they form particles 100-500 nm in diameter which can penetrate cell membranes and enter cells. The complex of DNA and liposomes is resistant to nuclease degradation, thus improving the success rates of gene delivery. Flu-like inflammatory responses have been generated, thought largely to be due to the presence of unmethylated $\mathrm{CpG}$ dinucleotides on the plasmid DNA. Our Consortium has recently reported the development of a CpGfree plasmid, ${ }^{24}$ shown in preclinical models to abrogate this inflammatory response. A further modification, replacing the CMV promoter with a humanized one, has also conferred a significantly increased duration of expression.

\section{Which cells to target?}

Maximal CFTR expression in non-CF airways occurs in the submucosal glands and in the surface epithelium of the distal small airways..$^{25,26}$ Topical application via inhalation is likely to target the surface epithelium, but is less likely to reach the deeper submucosal gland cells. Whether or not gene transfer to these cells will be necessary for clinical effect remains to be determined. Although there is increasing understanding of the stem cell populations at various levels throughout the airway, methods to target these cells, which are usually not accessible directly on the airway surface, and to achieve long-term expression are being explored, but have not yet reached the stage of clinical trials. ${ }^{27}$

\section{Current status of clinical trials}

Over 20 clinical trials have been reported to date. From these, summarized in Table 1, several common themes have emerged, which are outlined below.

\section{The proof of principle of CFTR gene transfer has been confirmed}

Trials have largely been designed around molecular or electrophysiological outcome measures; very few trials attempt to achieve (or measure) clinical benefit. However, levels of CFTR mRNA and protein are low in healthy, nonCF patients and currently available assays may not be sensitive enough to measure a clinically-beneficial level of gene transfer. In addition, because of the complex post-translational pathway required by CFTR, mRNA levels may in fact not correlate with levels of protein or degree of functional correction. Indeed, it is unknown how well either of these measures correlates with correction of the basic ion transport defect or with markers of clinical improvement. Correction of ion transport can be measured in vivo with transepithelial (nasal or bronchial mucosal) potential difference (PD). ${ }^{29}$ The basal PD in patients with $\mathrm{CF}$ is classically more negative and demonstrates a greater response to amiloride, due to the greater absorption of positively charged sodium ions into the epithelia via the epithelial sodium channel. Most sensitively, the chloride secretory capacity of the CF epithelia is blunted (in response to low chloride solution and isoproteronol, a c-AMP agonist). ${ }^{30,31}$ However, similar to the comments above concerning molecular correction, it is not completely clear how potential difference relates to clinical disease expression or how much change is necessary in which parameter(s) (chloride or sodium) to achieve clinical benefit. Interestingly, laboratory studies have demonstrated that changes in chloride secretion can be achieved following 


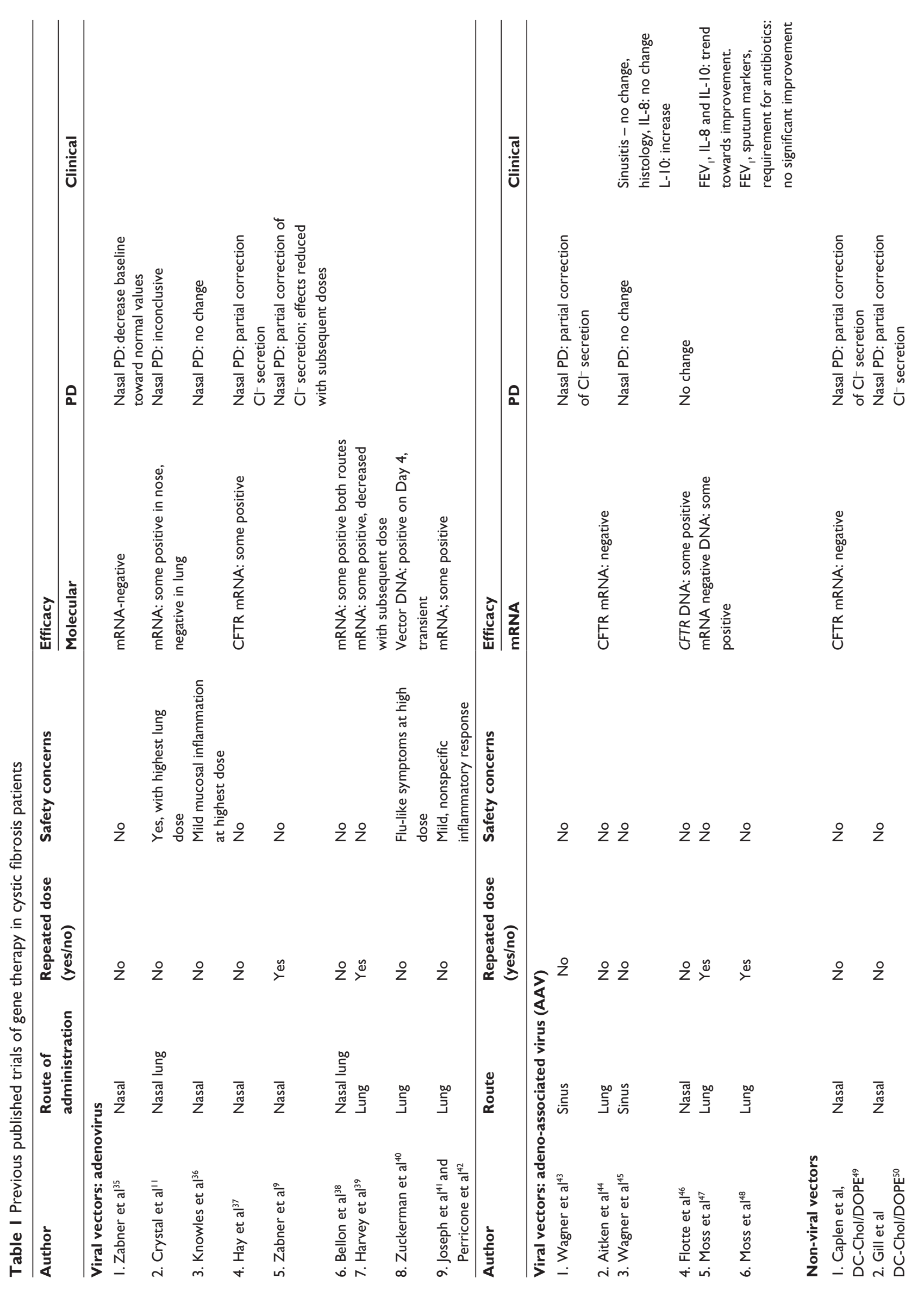


correction of a minority of cells, whereas correction of $\mathrm{Na}^{+}$ hyperabsorption likely reflects normal CFTR function in almost $100 \%$ of cells..$^{32}$ This may explain why improvements in chloride secretion have been observed in the absence, in general, of reduced sodium hyperabsorption (which may in fact be confused electrophysiologically with changes arising from inflammation). Residual chloride secretion is seen in some patients with classic CF and has been linked, at least in some cohorts, to milder disease, ${ }^{33}$ although this is not a consistent finding. ${ }^{34}$ Encouragingly in this regard, clinical trials of the CFTR potentiator, VX-770, which appears largely to improve chloride ion transport, have led to significant improvements in lung function; ${ }^{35}$ correction of $\mathrm{Na}^{+}$transport in addition to $\mathrm{Cl}^{-}$may not be required for clinical benefit. As can be seen in Table 1, molecular and electrophysiological results have been variable but with both viral and non-viral approaches, the proof of principle of CFTR gene transfer has been confirmed on this basis.

\section{Gene expression is reduced after subsequent doses of viral gene transfer agents}

We regard the inability to dose repeatedly to be a major limitation of current viral strategies and the main reason for the UK CF Gene Therapy Consortium to focus its first wave of research on non-viral approaches.

\section{Even non-viral approaches may induce an inflammatory response}

This may largely reflect components of the plasmid DNA, although it is possible that lipid-based complexes may trigger an inflammatory reaction, perhaps when taken up by pulmonary macrophages. Clearly, a severe inflammatory response in the already inflamed CF airway is undesirable and dosing strategies including the concomitant use of anti-inflammatory agents are under consideration.

\section{Evidence for clinical benefit is lacking to date}

The majority of clinical trials have not been designed to detect clinical benefit. The few that have included clinical outcomes have reported variable results: a reduction in inflammatory markers has been reported in both the sinuses (AAV) and sputum (cationic liposomes); one trial with AAV reported small but significant improvements in lung function, but this effect was not repeatable in a subsequent, larger trial. 


\section{Current challenges for gene therapy}

We believe that the current challenge is to move gene therapy from the proof-of-principle stage into one of clinical efficacy. To this end, the UK Cystic Fibrosis Gene Therapy Consortium was established several years ago. It brought together the three clinical research centers within the UK with previous CF gene therapy clinical trial experience: Oxford University, Edinburgh University and Imperial College London (and Royal Brompton Hospital). The consortium has two waves of research:

\section{Wave I}

We sought to identify the best, currently available gene transfer agent that could be used in a trial designed to assess clinical benefit. On the basis that such clinical benefit would require a long duration of CFTR expression we assumed that this would require repeated administration and therefore, based on all data available both in-house and from other groups at that time, a non-viral gene transfer system was required. In addition, the optimal agent needed to be safe, nebulizable and manufacturable to good manufacturing practice standards. On the basis of laboratory and preclinical testing, the optimal non-viral vector was found to be Genzyme's GL67 (Genzyme Corporation, Cambridge, MA) which we have co-formulated (GL67A) with the neutral lipid dioleoylphosphatidylethanolamine, to facilitate pDNA endosomal escape, along with small amounts of a polyethylene glycol-containing lipid (DMPEPEG5000) to aid stability. We are currently testing this, in combination with the Consortium's plasmid pGM169 (CpG-depleted, long-duration, as described above) in a single application, safety, and dose-finding study. Primary outcome is safety assessed by clinical assessment, serum inflammatory markers and lung function. We are also taking the opportunity to assess gene expression (mRNA) and function (upper and lower airway potential difference). Following this, we will look for clinical benefit in a repeated dose study. Outcome measures for gauging "clinical benefit" have been assessed in parallel in both interventional and observational settings.

\section{Wave 2}

This is the more experimental and futuristic focus of the Consortium. We are designing a body of work to develop pseudotyped lentiviruses, expressing the Sendai virus F (fusion) and HN (hemagglutinin neuraminidase) as a potentially highly efficient, long-lasting and repeatable gene transfer methodology.

\section{Conclusion}

To conclude, over the years since the CFTR gene was discovered, the proof of principle of gene transfer to the airway has been confirmed and partial correction in ion transport achieved. We are currently poised on the brink of a new era, understanding whether and to what extent this can translate into clinical benefit for patients with this disease.

\section{Disclosure}

The authors report no conflicts of interest in this work.

\section{References}

1. Welsh MJ, Smith AE. Molecular mechanisms of CFTR chloride channel dysfunction in cystic fibrosis. Cell. 1993;73(7):1251-1254.

2. Cystic Fibrosis Foundation. Patient Registry: Annual Data Report 2010. Bethesda, MD: Cystic Fibrosis Foundation; 2010

3. Tarran R, Button B, Picher M, et al. Normal and cystic fibrosis airway surface liquid homeostasis. The effects of phasic shear stress and viral infections. J Biol Chem. 2005;280(42):35751-35759.

4. Muhlebach MS, Noah TL. Endotoxin activity and inflammatory markers in the airways of young patients with cystic fibrosis. Am J Respir Crit Care Med. 2002;165(7):911-915.

5. Karp CL, Flick LM, Park KW, et al. Defective lipoxin-mediated anti-inflammatory activity in the cystic fibrosis airway. Nat Immunol. 2004;5(4):388-392.

6. Hartl D, Griese M, Kappler M, et al. Pulmonary T(H)2 response in Pseudomonas aeruginosa-infected patients with cystic fibrosis. J Allergy Clin Immunol. 2006;117(1):204-211.

7. Ashlock MA, Olson ER. Therapeutics development for cystic fibrosis: a successful model for a multisystem genetic disease. Annu Rev Med. $2011 ; 62: 107-125$

8. Kitson C, Angel B, Judd D, et al. The extra-and intracellular barriers to lipid and adenovirus-mediated pulmonary gene transfer in native sheep airway epithelium. Gene Ther. 1999;6(4):534-546.

9. Zabner J, Ramsay BW, Meeker DP, et al. Repeat administration of an adenovirus vector encoding cystic fibrosis transmembrane conductance regulator to the nasal epithelium of patients with cystic fibrosis. $J$ Clin Invest. 1996;97(6):1504-1511.

10. Schwarzt DA, Quinn TJ, Thorne PS, Sayeed S, Yi AK, Krieg AM. CpG motifs in bacterial DNA cause inflammation in the lower respiratory tract. J Clin Invest. 1997;100(1):68-73.

11. Crystal RG, McElvaney NG, Rosenfeld MA, et al. Administration of an adenovirus containing the human CFTR cDNA to the respiratory tract of individuals with cystic fibrosis. Nat Gene. 1994;8(1):42-51.

12. Walters RW, Grunst T, Bergelson JM, et al. Basolateral localization of fiber receptors limits adenovirus infection from the apical surface of airway epithelia. J Biol Chem. 1999;274(15):10219-10226.

13. Parsons DW, Grubb BR, Johnson LG, Boucher RC. Enhanced in vivo airway gene transfer via transient modification of host barrier properties with a surface-active agent. Hum Gene Ther. 1998;9(18):2661-2272.

14. Weiss DJ, Beckett T, Bonneau L, Young J, Kolls JK, Wang G. Transient increase in lung epithelial tight junction permeability: an additional mechanism for enhancement of lung transgene expression by perfluorochemical liquids. Mol Ther. 2003;8(6):927-935.

15. Zhang L, Wang D, Fischer H, et al. Efficient expression of CFTR function with adeno-associated virus vectors that carry shortened CFTR genes. Proc Natl Acad Sci U S A. 1998;95(17):10158-10163.

16. Song Y, Lou HH, Boyer JL, et al. Functional cystic fibrosis transmembrane conductance regulator expression in cystic fibrosis airway epithelial cells by AAV6.2-mediated segmental trans-splicing. Hum Gene Ther. 2009;20(3):267-281. 
17. Ferrari S, Griesenbach U, Iida A, et al. Sendai virus-mediated CFTR gene transfer to the airway epithelium. Gene Ther. 2007;14:1371-1379.

18. Bishop AE. Pulmonary epithelial stem cells. Cell Prolif. 2004;37(1): $89-96$.

19. Hacein-Bey-Abina S, Garrigue A, Wang GP, et al. Insertional oncogenesis in 4 patients after retrovirus-mediated gene therapy of SCID-X1. J Clin Invest. 2008;118(9):3132-3142.

20. Johnson LG, Olsen JC, Naldini L, Boucher RC. Pseudotyped human lentiviral vector-mediated gene transfer to airway epithelia in vivo. Gene Ther. 2000;7(7):568-574.

21. Griesenbach U, Ferrari S, Geddes DM, Alton EWFW. Gene therapy progress and prospects: cystic fibrosis. Gene Ther. 2002;9(20): 1344-1350.

22. Delenda C. Lentiviral vectors: optimization of packaging, transduction and gene expression. J Gene Med. 2004;6 Suppl 1:S125-S138.

23. Mitomo K, Griesenbach U, Inoue M, et al. Toward gene therapy for cystic fibrosis using a lentivirus pseudotyped with Sendai virus envelopes. Mol Ther. 2010;18(6):1173-1182.

24. Hyde SC, Pringle IA, Abdullah S, et al. CpG-free plasmids confer reduced inflammation and sustained pulmonary gene expression. Nat Biotechnol 2008;26(5):549-551.

25. Engelhardt JF, Yankaskas JR, Ernst SA, et al. Submucosal glands are the predominant site of CFTR expression in the human bronchus. Nat Genet. 1992;2(3):240-248.

26. Engelhardt JF, Zepeda M, Cohn JA, Yankaskas JR, Wilson JM. Expression of the cystic fibrosis gene in adult human lung. JClin Invest. 1994;93(2):737-749.

27. Sinn PL, Anthony RM, McCray PB Jr. Genetic therapies for cystic fibrosis lung disease. Hum Mol Genet. 2011;20(R1):R79-R86.

28. Davies JC, Alton EW. Gene therapy for cystic fibrosis. Proc Am Thorac Soc. 2010;7(6):408-414.

29. Griesenbach U, Smith SN, Farley R, Singh C, Alton EW. Validation of nasal potential difference measurements in gut-corrected CF knockout mice. Am J Respir Cell Mol Biol. 2008;39(4):490-496.

30. Knowles MR, Paradiso AM, Boucher RC. In vivo nasal potential difference: techniques and protocols for assessing efficacy of gene transfer in cystic fibrosis. Hum Gene Ther. 1995;6(4):445-455.

31. Accurso FJ, Rowe SM, Clancy JP, et al. Effect of VX-770 in persons with cystic fibrosis and the G551D-CFTR mutation. $N$ Engl $J$ Med. 2010;363(21):1991-2003.

32. Johnson LG, Boyles SE, Wilson J, Boucher RC. Normalization of raised sodium absorption and raised calcium-mediated chloride secretion by adenovirus-mediated expression of cystic fibrosis transmembrane conductance regulator in primary human cystic fibrosis airway epithelial cells. J Clin Invest. 1995;95(3):1377-1382.

33. Bronsveld I, Mekus F, Bijman J, et al. Chloride conductance and genetic background modulate the cystic fibrosis phenotype of Delta F508 homozygous twins and siblings. J Clin Invest. 2001;108(11): 1705-1715.

34. Simmonds NJ, D’Souza L, Roughton M, Alton EW, Davies JC, Hodson ME. Cystic fibrosis and survival to 40 years: a study of cystic fibrosis transmembrane conductance regulator function. Eur Respir $J$. 2011;37(5):1076-1082.

35. Zabner J, Couture LA, Gregory RJ, Graham SM, Smith AE, Welsh MJ. Adenovirus-mediated gene transfer transiently corrects the chloride transport defect in nasal epithelia of patients with cystic fibrosis. Cell. 1993;75(2):207-216.

36. Knowles MR, Hohneker KW, Zhou Z, et al. A controlled study of adenoviral-vector mediated gene transfer in the nasal epithelium of patients with cystic fibrosis. $N$ Engl J Med. 1995;333(13):823-831.

37. Hay JG, McElvaney NG, Herena J, Crystal RG. Modification of nasal epithelial potential differences of individuals with cystic fibrosis consequent to local administration of a normal CFTR cDNA adenovirus gene transfer vector. Hum Gene Ther. 1995;6(11):1487-1496.

38. Bellon G, Michel-Calemard L, Thouvenot D, et al. Aerosol administration of a recombinant adenovirus expressing CFTR to cystic fibrosis patients: a phase I clinical trial. Hum Gene Ther. 1997;8(1):15-25.
39. Harvey BG, Leopold PL, Hackett NR, et al. Airway epithelial CFTR mRNA expression in cystic fibrosis patients after repetitive administration of a recombinant adenovirus. J Clin Invest. 1999;104(9):1245-1255.

40. Zuckerman JB, Robinson CB, McCoy KS, et al. A phase I study of adenovirus-mediated transfer of the human cystic fibrosis transmembrane conductance regulator gene to a lung segment of individuals with cystic fibrosis. Hum Gene Ther. 1999;10(18):2973-2985.

41. Joseph PM, O'Sullivan BP, Lapey A, et al. Aerosol and lobar administration of a recombinant adenovirus to individuals with cystic fibrosis. I. Methods, safety, and clinical implications. Hum Gene Ther. 2001; 12(11):1369-1382.

42. Perricone MA, Morris JE, Pavelka K, et al. Aerosol and lobar administration of a recombinant adenovirus to individuals with cystic fibrosis. II. Transfection efficiency in airway epithelium. Hum Gene Ther. 2001; 12(11):1383-1394.

43. Wagner JA, Messner AH, Moran ML, et al. Safety and biological efficacy of an adeno-associated virus vector-cystic fibrosis transmembrane regulator (AAV-CFTR) in the cystic fibrosis maxillary sinus. Laryngoscope. 1999;109(2 Pt 1):266-274.

44. Aitken ML, Moss RB, Waltz DA, et al. A phase I study of aerosolized administration of $\operatorname{tg} \mathrm{AAVCF}$ to cystic fibrosis subjects with mild lung disease. Hum Gene Ther. 2001;12(15):1907-1916.

45. Wagner JA, Nepomuceno IB, Messner AH, et al. A phase II, doubleblind, randomized, placebo-controlled clinical trial of tgAAVCF using maxillary sinus delivery in patients with cystic fibrosis with antrostomies. Hum Gene Ther. 2002;13(11):1349-1359.

46. Flotte TR, Zeitlin PL, Reynolds TC, et al. Phase I trial of intranasal and endobronchial administration of a recombinant adeno-associated virus serotype 2 (rAAV2)-CFTR vector in adult cystic fibrosis patients: a two-part clinical study. Hum Gene Ther. 2003;14(11):1079-1088.

47. Moss RB, Rodman D, Spencer LT, et al. Repeated adeno-associated virus serotype 2 aerosol-mediated cystic fibrosis transmembrane regulator gene transfer to the lungs of patients with cystic fibrosis: a multicenter, double-blind, placebo-controlled trial. Chest 2004;125(2):509-521.

48. Moss RB, Milla C, Colombo J, et al. Repeated aerosolized AAV-CFTR for treatment of cystic fibrosis: a randomized placebo-controlled phase 2B trial. Hum Gene Ther. 2007;18(8):726-732.

49. Caplen NJ, Alton EW, Middleton PG, et al. Liposome-mediated CFTR gene transfer to the nasal epithelium of patients with cystic fibrosis. Nat Med. 1995;1(1):39-46.

50. Gill DR, Southern KW, Mofford KA, et al. A placebo-controlled study of liposome-mediated gene transfer to the nasal epithelium of patients with cystic fibrosis. Gene Ther. 1997;4(3):199-209.

51. Porteous DJ, Dorin JR, McLachlan G, et al. Evidence for safety and efficacy of DOTAP cationic liposome mediated CFTR gene transfer to the nasal epithelium of patients with cystic fibrosis. Gene Ther. 1997; 4(3):210-218.

52. Hyde SC, Southern KW, Gileadi U, et al. Repeat administration of DNA/ liposomes to the nasal epithelium of patients with cystic fibrosis. Gene Ther. 2000;7(13):1156-1165.

53. Zabner J, Cheng SH, Meeker D, et al. Comparison of DNA-lipid complexes and DNA alone for gene transfer to cystic fibrosis airway epithelia in vivo. J Clin Invest. 1997;100(6):1529-1537.

54. Alton EW, Stern M, Farley R, et al. Cationic lipid-mediated CFTR gene transfer to the lungs and nose of patients with cystic fibrosis: a double-blind placebo-controlled trial. Lancet. 1999;353(9157):947-954.

55. Ruiz FE, Clancy JP, Perricone MA, et al. A clinical inflammatory syndrome attributable to aerosolized lipid-DNA administration in cystic fibrosis. Hum Gene Ther. 2001;12(7):751-761.

56. Konstan MW, Davis PB, Wagener JS, et al. Compacted DNA nanoparticles administered to the nasal mucosa of cystic fibrosis subjects are safe and demonstrate partial to complete cystic fibrosis transmembrane regulator reconstitution. Hum Gene Ther. 2004;15(12): $1255-1269$. 
The Application of Clinical Genetics

Dovepress

\section{Publish your work in this journal}

The Application of Clinical Genetics is an international, peer-reviewed open access journal that welcomes laboratory and clinical findings in the field of human genetics. Specific topics include: Population genetics; Functional genetics; Natural history of genetic disease; Management of genetic disease; Mechanisms of genetic disease; Counselling and

ethical issues; Animal models; Pharmacogenetics; Prenatal diagnosis; Dysmorphology. The manuscript management system is completely online and includes a very quick and fair peer-review system, which is all easy to use. Visit http://www.dovepress.com/testimonials.php to read real quotes from published authors.

Submit your manuscript here: http://www.dovepress.com/the-application-of-clinical-genetics-journal 